\title{
In vitro characterization of jellyfish venom fibrin(ogen)olytic enzymes from Nemopilema nomurai
}

Seong Kyeong Bae ${ }^{1 \dagger}$, Hyunkyoung Lee ${ }^{4 \dagger}$, Yunwi Heo ${ }^{3}$, Min Jung Pyo ${ }^{1}$, Indu Choudhary', Chang Hoon Han², Won Duk Yoon ${ }^{2}$, Changkeun Kang ${ }^{1}$ and Euikyung Kim ${ }^{1,4^{*}}$

\begin{abstract}
Background: Because jellyfish are capable of provoking envenomation in humans, they are considered hazardous organisms. Although the effects of their toxins are a matter of concern, information on the venom components, biological activity and pathological mechanisms are still scarce. Therefore, the aim of the present study was to investigate a serine protease component of Nemopilema nomurai jellyfish venom ( $\mathrm{NnV}$ ) and unveil its characteristics.
\end{abstract}

Methods: To determine the relationship between fibrinolytic activity of NnV and the serine protease, fibrin zymography was performed using metalloprotease and serine protease inhibitors. The biochemical characterization of serine proteases of NnV were determined by the amidolytic assay. Fractions with fibrinolytic activity were obtained by DEAE cation exchange column.

Results: NnV displayed fibrinolytic activities with molecular masses of approximately 70, 35, 30, and $28 \mathrm{kDa}$. The fibrinolytic activity of $\mathrm{NnV}$ was completely obliterated by phenylmethylsulfonyl fluoride, a prototype serine protease inhibitor. Based on amidolytic assays using chromogenic substrates specific for various kinds of serine proteases, NnV predominantly manifested a chymotrypsin-like feature. Its activity was completely eliminated at low pH $(<6)$ and high temperatures $\left(>37^{\circ} \mathrm{C}\right)$. Some metal ions $\left(\mathrm{Co}^{2+}, \mathrm{Cu}^{2+}, \mathrm{Zn}^{2+}\right.$ and $\left.\mathrm{Ni}^{2+}\right)$ strongly suppressed its fibrinolytic activity, while others $\left(\mathrm{Ca}^{2+}\right.$ and $\mathrm{Mg}^{2+}$ ) failed to do so. Isolation of a serine protease with fibrionolytic activity from NnV revealed that only p3 showed the fibrinolytic activity, which was completely inhibited by PMSF.

Conclusion: The present study showed that $N$. nomurai jellyfish venom has a chymotrypsin-like serine protease with fibrinolytic activity. Such information might be useful for developing clinical management of jellyfish envenomation and pharmacological agents with therapeutic potential for thrombotic diseases in the future.

Keywords: Nemopilema nomurai, Jellyfish venom, Chymotrypsin, Serine protease, Fibrinolytic activity

\section{Background}

Over the last decade, there has been a dramatic increase of global jellyfish blooming from many places in the world, including the oceans of Korea, China, and Japan. Jellyfish blooming can cause a number of social, economic, and public health problems. Power plants may shutdown due to jellyfish clogging the cooling water

\footnotetext{
* Correspondence: ekim@gnu.ac.kr

${ }^{\dagger}$ Equal contributors

${ }^{1}$ College of Veterinary Medicine, Gyeongsang National University, Jinju 660-701, Korea

${ }^{4}$ Institute of Animal Medicine, Gyeongsang National University, Jinju, 660-701, Korea

Full list of author information is available at the end of the article
}

system. In addition, jellyfish can damage fishery industries and sting humans [1-3]. Jellyfish stinging is considered a serious envenomation for sea bathers due to its lifethreating effects, including diffused neurotoxicity, cardiovascular collapse, respiratory failure, hypotension, shock and even death [4-7]. However, only a few toxic components have been successfully identified from jellyfish venom. Their molecular mechanisms of actions remain unclear from toxicological/pathological point of view.

Nemopilema nomurai is a giant jellyfish with a bell size up to $2 \mathrm{~m}$ in diameter. This jellyfish is one of the dominant jellyfish species in Korean coast. Its sting accidents have been increasing every year [8]. N. nomurai 
venom causes various symptoms that are mild or severe such as itching, redness, edema, hypotension, shock, and even death [9]. To date, several reports revealed that $\mathrm{NnV}$ induces cardiotoxic, cytotoxic, dermonecrotic, hemolytic, myotoxic, and proteolytic effects in in vitro and in vivo studies [10-13]. Our previous study has demonstrated that $\mathrm{NnV}$ has a proteolytic activity which is closely associated with cytotoxicity in skin cells [13]. Cotreatment of $\mathrm{NnV}$ with 1, 10-phenanthroline (metalloprotease inhibitor) can suppress its proteolytic activity on gelatin, fibrin, and casein as well as its cytotoxicity [13]. Furthermore, it has been demonstrated that the metalloprotease activity of $\mathrm{NnV}$ plays an important role in dermal pathology by its envenomation [12]. $\mathrm{NnV}$ causes severe damage accompanied by collapse of skin barriers, hemorrhage, and neutrophil infiltration in dermis. Treatment with tetracycline (a metalloprotease inhibitor) can alleviate pathological skin lesion. Therefore, like snake venom, the proteolytic activity might play a central role in local pathological alterations caused by $N$. nomurai sting.

The proteolytic activity of venom is mainly associated with two protease groups: metalloprotease and serine protease. Serine protease is particularly abundant in snake venoms. It can directly affect the coagulation cascade [14]. It influences the degradation of coagulation factor, disturbance of platelet aggregation, and fibrinolysis, thus preventing clot formation and causing systemic bleeding, hypovolemia, and hemodynamic shock [14, 15]. Serine protease also influences cell differentiation, immune response, and digestion $[14,16]$. Transcriptomics and proteomics analysis have shown that serine protease is one toxic component in jellyfish venoms [17-19]. Our previous study has found a chymotrypsin-like serine protease in $\mathrm{NnV}$ and determined its full-length cDNA and gene sequence [20]. However, little information is available for serine protease in $\mathrm{NnV}$. Therefore, the objective of this study was to investigate the serine protease component of $\mathrm{NnV}$ and unveil its characteristics using various biochemical methods.

\section{Methods}

\section{Chemicals and reagents}

Fibrinogen (type I-S from bovine plasma), thrombin (from bovine plasma), 1, 10-phenanthroline, phenylmethanesulfonyl fluoride (PMSF), benzamidine and chromogenic substrates were purchased from Sigma Chemical Co. (USA). Ethylenediaminetetraacetic acid (EDTA) and $\beta$-mercaptoethanol were obtained from Amresco Chemical (USA). All other reagents used were of the purest grade available.

\section{Jellyfish nematocyst preparation}

Five different species of jellyfish samples were collected from various geographical locations around the coasts of
South Korea as follows: $N$. nomurai jellyfish from the Korea Strait along the coasts of Geoje in September 2012; Aurelia aurita from Masan in September 2012; Dactylometra quinquecirrha from Tongyoung in August 2011; Physalia physalis from the Jeju island in July 2012; and Carybdea brevipedalia from the South sea near Samcheonpo in August 2012. Only tentacles were collected and transferred immediately to a laboratory for further preparation. Nematocysts were isolated from the dissected tentacles as described by the method of Bloom with slight modifications [21].

In brief, dissected tentacles were rinsed with cold seawater to remove debris. The tentacles were placed in three volumes of cold seawater for $24 \mathrm{~h}$ with gentle swirling for $1 \mathrm{~h}$ once a day at $4{ }^{\circ} \mathrm{C}$. After autolysis for $24 \mathrm{~h}$ at $4{ }^{\circ} \mathrm{C}$, the supernatant was collected and centrifuged at $4000 \mathrm{~g}$ for $10 \mathrm{~min}$. The settled material was resuspended in fresh seawater and set for autolysis for $24 \mathrm{~h}$. This process was repeated for three days. The sediments were collected and centrifuged $4000 \mathrm{~g}$ for $10 \mathrm{~min}$ and washed several times with fresh distilled water by centrifugation $100 \mathrm{~g}$ at $4{ }^{\circ} \mathrm{C}$ for $5 \mathrm{~min}$ until debris around nematocysts was almost removed. Finally, the undischarged nematocysts were collected, lyophilized and stored at $-70{ }^{\circ} \mathrm{C}$ until use.

\section{Venom preparation}

Venom was extracted from the freeze-dried nematocysts using the technique described by Carrette and Seymour [22] with a minor modification. In brief, venom was extracted from $60 \mathrm{mg}$ of nematocyst powder using glass beads (approximately 8000 beads; $0.5 \mathrm{~mm}$ in diameter) and $1 \mathrm{~mL}$ of cold phosphate buffered saline (PBS, $\mathrm{pH}$ 7.4). These mixtures were shaken in a mini bead mill at $3000 \mathrm{rpm}(40 \mathrm{~s})$ for ten times with intermittent cooling on ice. The venom extracts were then transferred to a new microfuge tube and centrifuged $(13,000 \times \mathrm{g})$ at $4{ }^{\circ} \mathrm{C}$ for $30 \mathrm{~min}$. The supernatant was used as venom in the present study. Protein concentration of the venom was determined by using Bradford method and the venom was employed based on its protein concentration [23].

\section{SDS polyacrylamide gel electrophoresis (SDS-PAGE)}

Electrophoresis was carried out according to Laemmli method [24] using $12 \%$ separating gel and $4 \%$ stacking gel. The $\mathrm{NnV}$ was prepared in non-reducing sample buffer (4\% SDS, 125 mM Tris-HCl, pH 6.8, 20\% glycerol, $0.01 \%$ bromophenol blue) then stored at $-20{ }^{\circ} \mathrm{C}$ until use. $\mathrm{NnV}$ protein $(50 \mu \mathrm{g})$ was electrophoresed for $90 \mathrm{~min}$ at $100 \mathrm{~V}$ at constant voltages using Tris-glycine running buffer. The molecular weight markers, 10250 kDa (Precision Plus Protein ${ }^{\mathrm{Tm}}$ Standards, Bio-rad, USA) were run parallel with $\mathrm{NnV}$ for molecular weight estimation. Following electrophoresis, separated protein 
bands were stained with $0.125 \%$ Coomassie blue in $40 \%$ methanol, $10 \%$ acetic acid.

\section{Examination of fibrinolytic activity using fibrin zymography}

Fibrin was used as substrate for the evaluation of fibrinolytic activity in zymography assay. For this experiment, fibrinogen $(0.6 \mathrm{mg} / \mathrm{mL})$ and thrombin $(0.01$ unit/ $\mathrm{mL}$ ) dissolved in $20 \mathrm{mM}$ sodium phosphate buffer ( $\mathrm{pH}$ 7.4) was copolymerized with $12 \%$ polyacrylamide to prepare the respective zymography gel. The various venoms $(20 \mu \mathrm{g})$ to be analyzed were prepared in nonreducing sample buffer, then run on gels at $100 \mathrm{~V}$ at $4{ }^{\circ} \mathrm{C}$. After electrophoresis, SDS was removed by washing the gel twice for $30 \mathrm{~min}$ in $2.5 \%$ Triton $\mathrm{X}-100$. Then, the gel was incubated with $20 \mathrm{mM}$ Tris ( $\mathrm{pH} 7.4$ ), $0.5 \mathrm{mM}$ calcium chloride, $200 \mathrm{mM}$ sodium chloride at $37{ }^{\circ} \mathrm{C}$ for $16 \mathrm{~h}$ and the gel was stained with $0.125 \%$ Coomassie blue. Clear zones of the gel indicate regions of fibrinolytic activity. To know the effect of metal ions and protease inhibitors on fibrinolytic activity, the metal ions and protease inhibitors were added to incubation buffers [20 mM Tris ( $\mathrm{pH} 7.4)$, $200 \mathrm{mM}$ sodium chloride], and the gel stained as usual. All metal ions and inhibitors give a final concentration of $2 \mathrm{mM}$ except PMSF (1 mM).

\section{Fibrinogenolytic activity}

Fibrinogenolytic activity of $\mathrm{NnV}$ was investigated according to the method by Matsubara et al. [25]. Briefly, $15 \mu \mathrm{L}$ of bovine fibronogen $(20 \mathrm{mg} / \mathrm{mL})$ was incubated with $10 \mu \mathrm{L} \mathrm{NnV}$ and $5 \mu \mathrm{L}$ of reaction buffer $(\mathrm{pH} 7.4$, $200 \mathrm{mM}$ sodium chloride, $0.5 \mathrm{mM}$ calcium chloride, $20 \mathrm{mM}$ Tris) at $37^{\circ} \mathrm{C}$ for indicated times and doses. The digested products were analyzed using 7.5\% SDS-PAGE.

\section{Amidolytic activity assay}

In an attempt to evaluate cleavage specificity, the amidolytic activity of $\mathrm{NnV}$ was assessed using various chromogenic substrates: N-Succinyl-Ala-Ala-Ala- $\rho$ NA (for elastase), N $\alpha$ Benzoyl-DL-Arg- $\rho$ NA (for trypsin), N-(p-Tosyl)-Gly-ProLys-4 nitroanilide acetate salt (for plasmin), N-BenzoylPhe-Val-Arg- $p$-nitroanilide hydrochloride (for thrombin), $\mathrm{N}$-Succinyl-Ala-Ala-Pro-Phe- $\rho$ NA (for chymotrypsin). For the assays, each substrate was made up to $0.5 \mathrm{mM}$ and then incubated with $\mathrm{NnV}(0.1 \mathrm{mg} / \mathrm{mL})$ for $1 \mathrm{~h}$ at $37{ }^{\circ} \mathrm{C}$. The reactions were monitored every five minutes using PowerWave XS microreader (Biotek) at $405 \mathrm{~nm}$.

\section{Effects of $\mathrm{pH}$ and temperature on amidolytic activity of $\mathrm{NnV}$}

The effect of $\mathrm{pH}$ on the enzymatic activity of $\mathrm{NnV}$ was evaluated under diverse $\mathrm{pH}$ conditions. $\mathrm{NnV}$ was incubated with different $\mathrm{pH}$ buffers, including $0.5 \mathrm{M}$ acetate (pH 3 and 4), $0.1 \mathrm{M}$ phosphate $(\mathrm{pH} \mathrm{5,6,7}$ and 8) and
$0.5 \mathrm{M}$ glycine- $\mathrm{NaOH}\left(\mathrm{pH} 9,10\right.$ and 11) for $1 \mathrm{~h}$ at $4{ }^{\circ} \mathrm{C}$. It reacted against N-Succinyl-Ala-Ala-Pro-Phe- $\rho \mathrm{NA}$ (for chymotrypsin) substrate and the proteolysis of the substrate was detected at $405 \mathrm{~nm}$. Furthermore, the enzymatic activity was assessed at various temperature conditions at 4, 25, 37, 60 and $100{ }^{\circ} \mathrm{C}$. The residual activity was measured after incubation of $\mathrm{NnV}$ in different temperatures for $30 \mathrm{~min}$.

\section{Effects of metal ions and protease inhibitors on enzymatic activity of $\mathrm{NnV}$}

The substrate of N-Succinyl-Ala-Ala-Pro-Phe- $\rho$ NA (for chymotrypsin) was used to measure the effects of metal ions and inhibitors on the enzymatic activity of $\mathrm{NnV}$. For this assay, $\mathrm{NnV}$ was incubated with several divalent metal ions or protease inhibitors for $1 \mathrm{~h}$ and followed by reacting chymotrypsin substrate for $30 \mathrm{~min}$ at $37^{\circ} \mathrm{C}$.

\section{Isolation of fibrinolytic protease from $\mathbf{N}$. nomurai venom} Crude venom of $\mathrm{NnV}(180 \mathrm{mg})$ was dissolved in $10 \mathrm{mM}$ Tris- $\mathrm{HCl}$ buffer $(\mathrm{pH} 7.8)$ and centrifuged at $13000 \times g$ for $30 \mathrm{~min}$. The venom solution was resolved on DEAE column (GE Healthcare), previously dialyzed against extraction buffer at $4{ }^{\circ} \mathrm{C}$. The column was eluted with gradient concentration of $\mathrm{NaCl}$ from 0 to $0.8 \mathrm{M}$ at a flow rate of $1 \mathrm{~mL}$ per min. Each peak was tested for fibrinolytic activity and SDS-PAGE.

\section{Statistical analysis}

The results are expressed as mean \pm standard deviation (SD). One-way analysis of variance (ANOVA) was used to evaluate the significance of difference between the two mean values. The values of $p$ considered statistically significant were $p<0.01$ and $p<0.05$.

\section{Results}

SDS-PAGE and fibrinolytic activity of $\mathrm{NnV}$

To compare the fibrinolytic activity between different jellyfish species, their venom proteins were loaded into fibrin zymogrpahy. The fibrinolytic activity indicated venom of three species, namely N. nomurai, A. aurita and P. physalis, but not D. quinquecirrha or C. brevipedalia. Among these, $P$. physalis venom was highly potent for fibrin degradation and its molecular weight was above $25 \mathrm{kDa}$. N. nomurai and $A$. aurita venoms showed similar banding patterns, which were distributed in $60-80 \mathrm{kDa}$ and 25-37 kDa (Fig. 1a). The 90 and $70 \mathrm{kDa}$ bands showed more intense staining than other bands.

In fibrin zymogrpahy, strong fibrinolytic activity was correlated with a molecular weight of approximately $70 \mathrm{kDa}$, while weaker hydrolytic activity was found for the three bands with molecular masses between 37 and $25 \mathrm{kDa}$ (Fig. 1b). Fibrinolytic enzymes were categorized into two groups (metalloprotease and serine protease) 

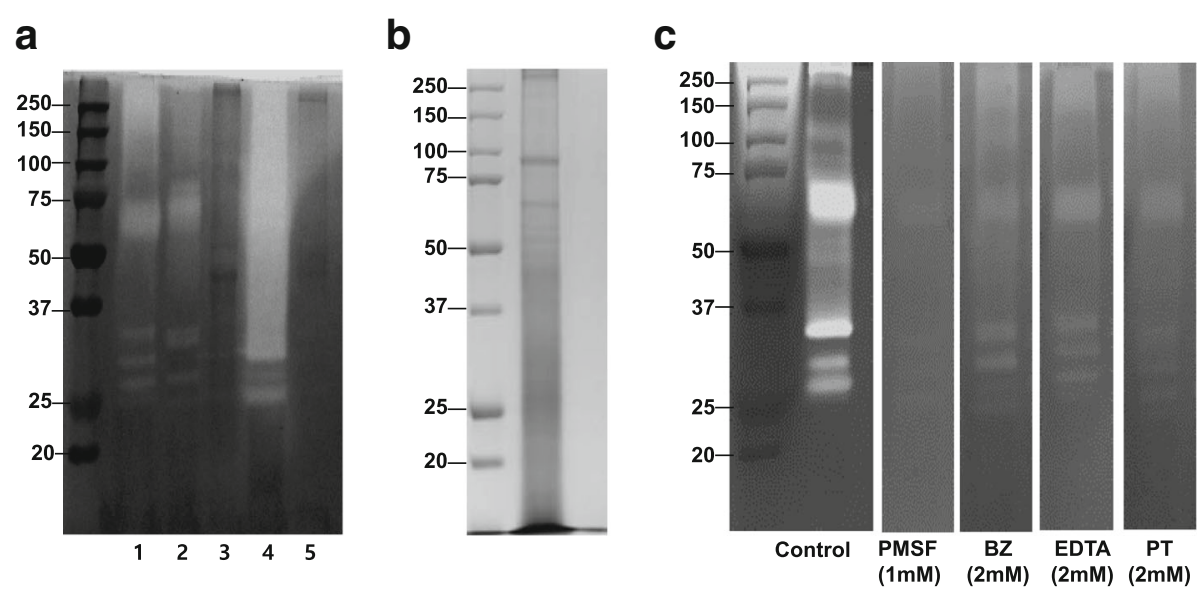

Fig. 1 SDS-PAGE profile and fibrinolytic activity of NnV. a We compared the fibrinolytic activity between jellyfish species. Lane $1-\mathrm{N}$. nomurai; lane 2 - A. aurita; lane 3 - D. quinquecirrha; lane 4 - P. physalis, lane 5 - C. brevipedalia. b NnV (50 $\mu \mathrm{g})$ was submitted to SDS electrophoresis under non-reducing conditions. The gels were stained with $0.125 \%$ Coomassie blue. c Fibrin zymography of NnV with various protease inhibitors, including PMSF (1 mM), BZ (2 mM), EDTA (2 mM) and PT (2 mM). Clear zones in the fibrin gel indicated regions of proteolytic activity

according to their action mechanisms and site. To determine which kind of protease was associated with the fibrionolytic activity of $\mathrm{NnV}$, broad inhibitors for metalloprotease [EDTA and 1, 10-Phenanthroline (PT)] and serine protease [PMSF and benzamidine (BZ)] were incubated with $\mathrm{NnV}$. Results showed that all inhibitors partially inhibited the fibrinolytic activity of NnV. However, only PMSF at a low concentration of $1 \mathrm{mM}$ showed strong inhibitory effect on its fibrinolytic activity (Fig. 1c). These results suggest that serine proteases play a more important role in the fibrinolytic activity of $\mathrm{NnV}$ than metallorproteases.

\section{Fibrinogenolytic activity of $\mathrm{NnV}$}

The fibrinogenolytic activity of $\mathrm{NnV}$ was analyzed by SDS-PAGE. NnV degraded both $\alpha$-chain and $\beta$-chain of fibrinogen in dose- and time-dependent manners
(Fig. $2 \mathrm{a}$ and $\mathrm{b}$ ). The $\alpha$-chain of fibrinogen was immediately digested after incubation with $\mathrm{NnV}$. Its complete degradation was observed at $360 \mathrm{~min}$ after incubation with $\mathrm{NnV}$. The $\beta$-chain of fibrinogen began to be degraded at $360 \mathrm{~min}$ after incubation with $\mathrm{NnV}$. However, $\gamma$-chain of fibrinogen was not affect by NnV.

\section{Amidolytic activity of $\mathrm{NnV}$}

$\mathrm{NnV}$ failed to degrade elastase, trypsin, thrombin, and plasmin substrates. However, it specifically exhibited hydrolytic activity against N-Succinyl-Ala-AlaPro-Phe- $\rho$ NA substrate (for chymotrypsin) (Fig. 3a). In addition, such enzymatic activity of $\mathrm{NnV}$ on chymotrypsin substrate was strongly inhibited by PMSF (Fig. 3b).
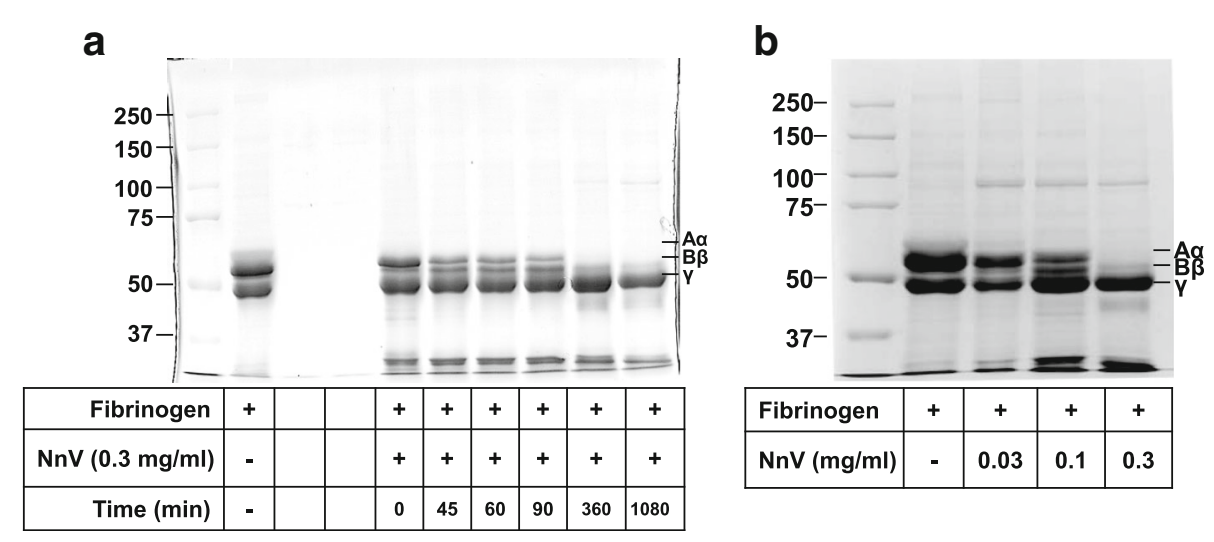

Fig. 2 Fibrinogenolytic activity of NnV. NnV was incubated with fibrinogen $(20 \mathrm{mg} / \mathrm{mL})$ for the indicated (a) times and (b) doses at $37^{\circ} \mathrm{C}$. The mixture samples were electrophoresed in the 7.5\% SDS-PAGE and stained with Coomassie blue. Fibrinogen consists of three polypeptides chains $a, \beta$ and $\gamma$ 

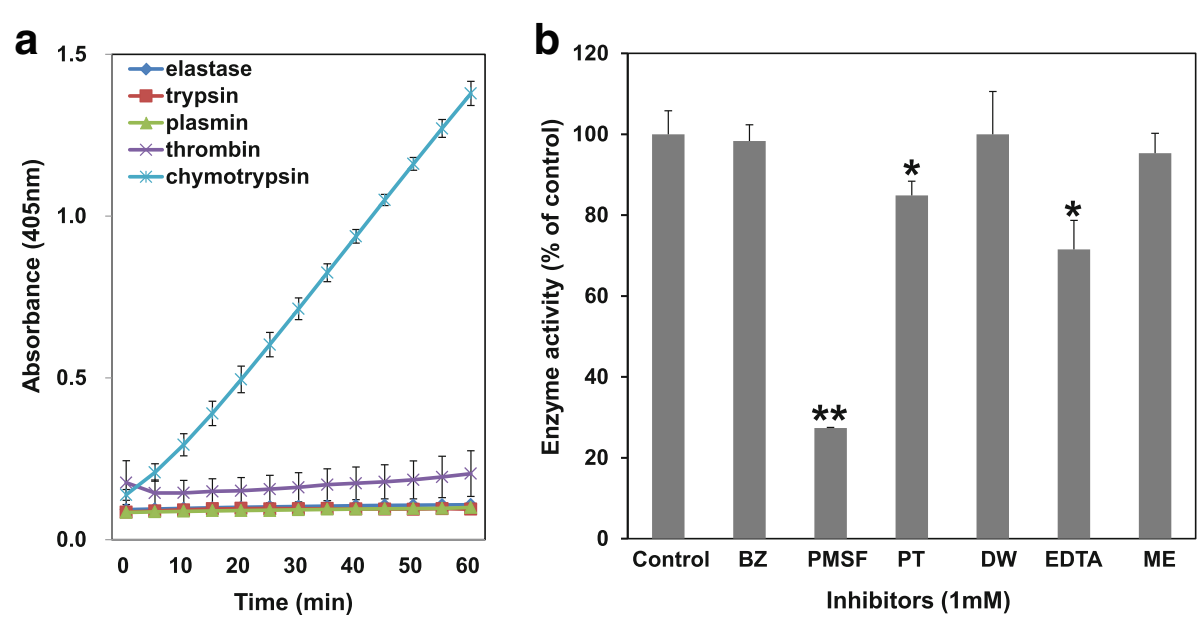

Fig. 3 The catalytic activity of NnV on several chromogenic substrates. a NnV was preincubated with different substrates [N-Succinyl-Ala-Ala-Ala$\rho \mathrm{NA}$ (for elastase), Na-Benzoyl-DL-Arg- $\rho \mathrm{NA}$ (for trypsin), N-(p-Tosyl)-Gly-Pro-Lys- $\rho \mathrm{NA}$-acetate salt (for plasmin), N-Benzoyl-Phe-Val-Arg- $\rho \mathrm{NA}$-HCl (for thrombin), N-Succinyl-Ala-Ala-Pro-Phe- $\rho \mathrm{NA}$ (for chymotrypsin)], $0.5 \mathrm{mM}$ for $1 \mathrm{~h}$. The catalytic activity of NnV was assayed at $405 \mathrm{~nm}$. b NnV was preincubated with different protease inhibitors $(1 \mathrm{mM})$, followed by reacting chymotrypsin substrate for $30 \mathrm{~min}$. Data represent as mean \pm SD from the three fields ${ }^{*} p<0.05$ and ${ }^{* *} p<0.01$, compared to control

\section{Hydrolytic activity of $\mathrm{NnV}$ is dependent on $\mathrm{pH}$, temperature, metal ions, and protease inhibitors}

The effect of $\mathrm{pH}$ on the enzymatic activity of $\mathrm{NnV}$ was determined using buffers at various $\mathrm{pH}$ values. The enzymatic activity of $\mathrm{NnV}$ on chymotrypsin substrate was stable and higher at neutral $(\mathrm{pH} 7)$ and basic $(\mathrm{pH} 8,9$, 10 and 11) $\mathrm{pH}$ conditions (Fig. 4a). However, its activity was unstable and lost under acidic conditions. The optimum temperature condition for its activity was found to be between 4 and $37{ }^{\circ} \mathrm{C}$. However, its activity was lost at high temperature including 60 and $100{ }^{\circ} \mathrm{C}$ (Fig. 4b). The effects of various metal ions on its enzymatic activity were also examined. $\mathrm{Ca}^{2+}$ and $\mathrm{Mg}^{2+}$ failed to activate or inhibit its enzymatic activity and fibrinolytic activity. However, $\mathrm{Co}^{2+}, \mathrm{Mn}^{2+}$, and $\mathrm{Ni}^{2+}$ showed slightly inhibitory effect on its enzymatic and fibrinolytic activity (Fig. 4c and d). Particularly, $\mathrm{Cu}^{2+}$ and $\mathrm{Zn}^{2+}$ exerted completely inhibitory effects on its activities.

\section{Purification of NnV with fibrinolytic activity}

After separating $\mathrm{NnV}$ on DEAE column, three peaks were obtained and the fibrionolytic activity of each peak was evaluated using fibrin zymography. Peak 3 (P3, Fr 11-15) showed fibrinolytic activity with two bands, whereas P1 and P2 failed to show any band (Fig. 5b). To determine whether the fibrinolytic activity of P3 was associated with serine protease, fibrin zymography was performed using typical protease inhibitors EDTA and PMSF. It was found that PMSF abolished the fibrinolytic activity of P3, but EDTA did not (Fig. 5c). However, the protein amount of P3 was small and the matching band with fibrinolytic activity at $35 \mathrm{kDa}$ in P3 was very weak (Fig. 5d).

\section{Discussion}

Several reports have demonstrated that jellyfish venom consists of various bioactive substances, including cytolysins, neurotoxins, peptides and proteases [13, 20, 26-28]. Unlike other venoms (snake, scorpion and spider), jellyfish venom is not secreted from venom glands or injected through specialized nematocysts that are present all over the cnidarians. Hence, it is very difficult to obtain pure jellyfish venom due to poor yield, besides being a timeconsuming and technically challenging process [29]. Although it is not easy to isolate and characterize individual jellyfish venom components, their characterization is very important in various aspects, including clinical management, development of therapeutic agents, and pharmaceutical application.

Our previous study has revealed that $\mathrm{NnV}$ contains abundant proteolytic enzymes responsible for dermonecrosis and cytotoxicity after stings $[12,13]$. Among proteolytic activities, fibrinolytic activity is an established mediator of toxicity in various animal venoms, especially snake venoms. Fibrinolytic enzymes may interfere with coagulation and fibrin(ogen)olytic systems, leading to systemic bleeding, coagulopathy, hypovolemia, and hemodynamic shock $[14,15,30]$. In our previous study, we reported the fibrinolytic activity of $\mathrm{NnV}$, but it only 1,10-phenathroline was used as an enzymatic inhibitor. Therefore, the relationship between fibrinolytic activity and other proteases could not be excluded. Generally, proteases with fibrinolytic activity are closely associated with metalloproteases and serine proteases.

In order to determine which protease contributed to the fibrionolytic activity of $\mathrm{NnV}$, in this study fibrin zymography was performed using metalloprotease 


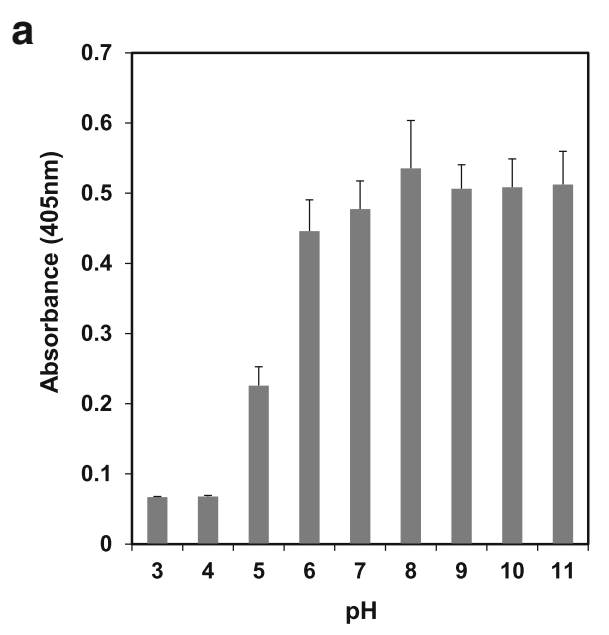

c

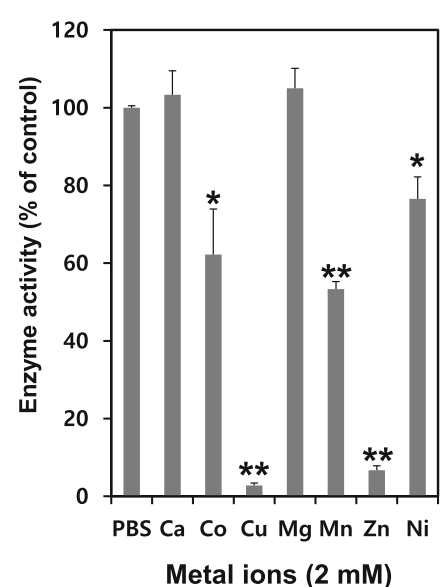

b

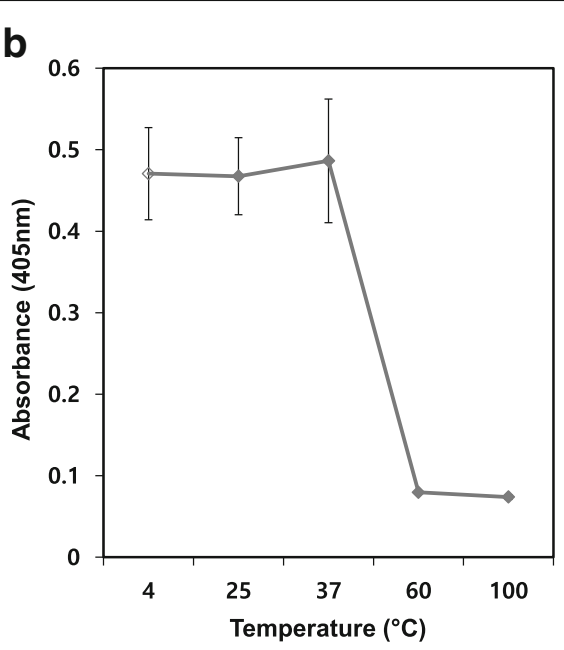

d

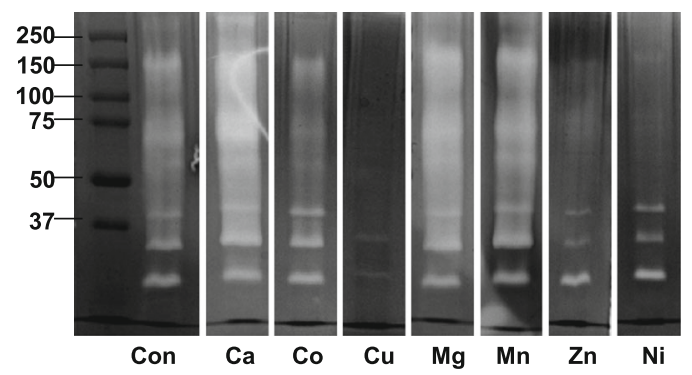

Fig. 4 The catalytic activity of $\mathrm{NnV}$ was dependent on $\mathrm{pH}$, temperature and metal ions. $\mathrm{NnV}(2 \mathrm{mg} / \mathrm{mL})$ was incubated under different (a) $\mathrm{pH}(3$, $4,5,6,7,8,9,10$ and 11), (b) temperatures $\left(4,25,37,60\right.$ and $\left.100{ }^{\circ} \mathrm{C}\right)$ and $(\mathbf{c})$ metal ions $\left(\mathrm{Ca}^{2+}, \mathrm{Co}^{2+}, \mathrm{Cu}^{2+}, \mathrm{Mg}^{2+}, \mathrm{Mn}^{2+}, \mathrm{Zn}^{2+}\right.$ and $\left.\mathrm{Ni}^{2+}\right)$ and added to chymotrypsin substrate for $30 \mathrm{~min}$ at $37^{\circ} \mathrm{C}$. $\mathbf{d ~ N n V ~}(20 \mu \mathrm{g})$ was submitted to fibrin zymography and incubated with metal ions $(10 \mathrm{mM})$ in zymography reaction buffer for $18 \mathrm{~h}$ at $37{ }^{\circ} \mathrm{C}$. The fibrin gel was stained with $0.125 \%$ Coomassie blue. Data represent as mean \pm SD from the three fields ${ }^{*} p<0.05$ and ${ }^{* *} p<0.01$, compared to control

inhibitors (EDTA and PT) and serine protease inhibitors (PMSF and BZ). Although EDTA and PT moderately inhibited the fibrinolytic activity, only PMSF completely inhibited it at a low concentration of $1 \mathrm{mM}$. Regarding its amidolytic activity, $\mathrm{NnV}$ only cleaved chymotrypsin substrates. Such activity was mostly inhibited by PMSF. Hence, we concluded that the fibrinolytic activity of $\mathrm{NnV}$ is mostly due to its serine proteases rather than metalloproteases. It demonstrated specific activity toward the chymotrypsin substrate.

The fibrinolytic activity of $\mathrm{NnV}$ was dependent on $\mathrm{pH}$, temperature, and metal ion concentration. Its fibrinolytic activity was strong at $\mathrm{pH}$ values of 8 to 11 . However, such activity was lost at $\mathrm{pH}$ values of 3 to 5 and weakened at $\mathrm{pH}$ values of 6 to 7 . To date, fibrinolytic enzymes derived from venoms have been found to be stable at $\mathrm{pH}$ values of 5.5 to 8.5 . For example, the fibrinolytic activity of neuwiedase, a metalloprotease from Bothrops neuwiedi snake, has been found to be strong at a pH range of 7.4 to 8.0 and Brevilysin L6 can persevere its activity at optimal pH of 8.5 to $9.5[31,32]$. Interestingly, fibrinolytic activity of $\mathrm{NnV}$ was found to be stable at basic conditions in this study, even at pH 11 . Its activity was fast at temperature below $37{ }^{\circ} \mathrm{C}$. However, this activity was sharply reduced when temperature was increased to be above $37{ }^{\circ} \mathrm{C}$. Furthermore, the fibrinolytic activity of $\mathrm{NnV}$ was strongly inhibited by $\mathrm{Zn}^{2+}$ and $\mathrm{Cu}^{2+}$ at $1 \mathrm{mM}$ in fibrin zymography and chromogenic substrate test.

Fibrinolytic enzymes commonly have fibrinogenolytic activities. Therefore, we performed assays to evaluate the fibrinogenolytic activity of $\mathrm{NnV}$ and found that $\mathrm{NnV}$ rapidly degraded $\alpha$-chain of fibrinogen followed by $\beta$-chain in a dose- and time-dependent manner. However, $\mathrm{NnV}$ 

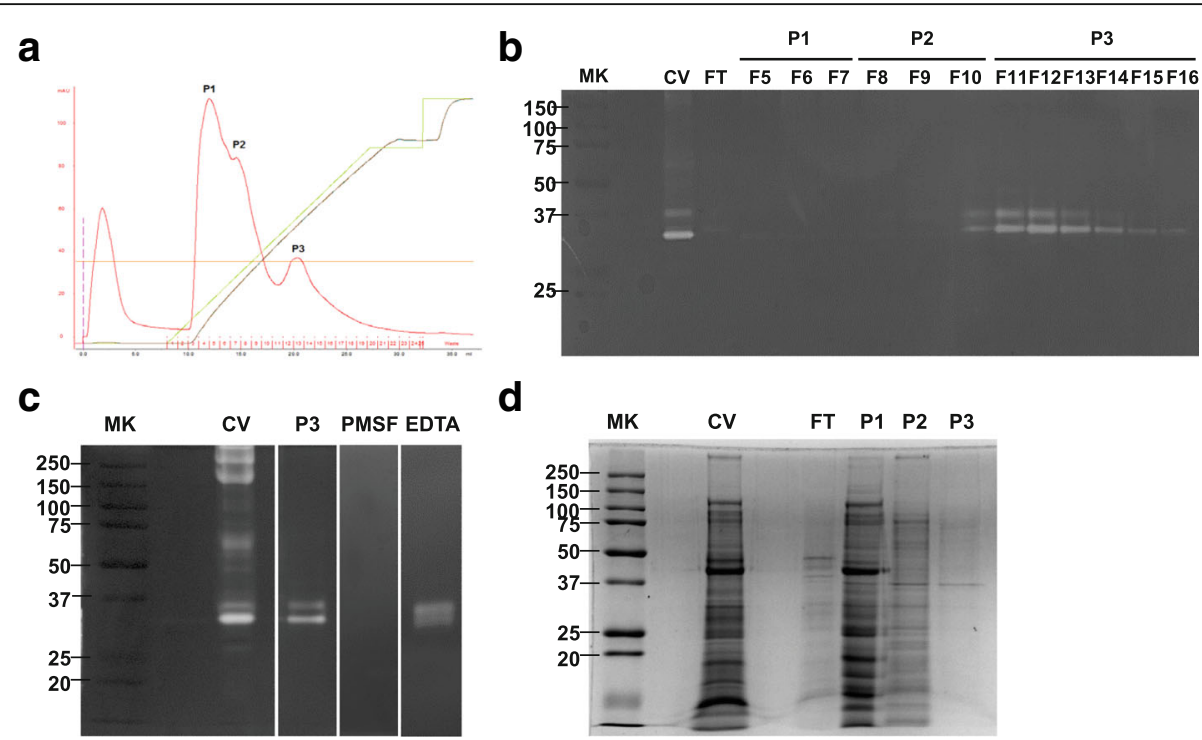

d

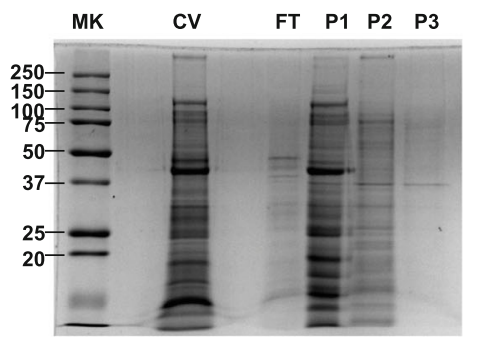

Fig. 5 The purification of serine protease from NnV. a Crude venom was dissolved in $10 \mathrm{mM}$ Tris- $\mathrm{HCl}(\mathrm{pH} 7.8)$ buffer and centrifuged for 30 min at $13000 \times \mathrm{g}$. The supernatant was loaded on a DEAE column and the proteins were eluted with a NaCl linear gradient of 0 to $80 \%$ at flow rate of $1 \mathrm{~mL} / \mathrm{min}$. $\mathbf{b}$ and $\mathbf{d}$ The fibrinolytic activity and protein profile of each fraction were evaluated by by zymography and SDS-PAGE. c The fibrinolytic activity was inhibited by PMSF $1 \mathrm{mM}$, but not by EDTA

failed to degrade $\gamma$-chain of fibrinogen. Most serine proteases in snake venoms preferentially hydrolyze $\beta$-chain of fibrin(ogen) with low activity toward $\alpha$-chain of fibrin(ogen). However, there are a few exceptions to such characteristic feature. For example, Dnase purified from the venom of Deinagkistrodon acutus is found to be a fibrinogenase that belongs to the serine protease family which preferentially digests $\alpha$-chain of fibrinogen in comparison with $\beta$-chain [33]. Despite the fact that fibrinogenase isolated from Agkistrodon halys brevicaudus is a metalloprotease, it can rapidly cleave $\beta$-chain of fibrinogen [32]. Although the fibrin(ogen)olytic enzymes of $\mathrm{NnV}$ belonged to the serine protease group, it preferentially degraded $\alpha$ chain than $\beta$-chain of fibrinogen.

To isolate fibrinolytic enzymes from $\mathrm{NnV}$, we performed chromatography on DEAE column. Among three peaks, only P3 showed fibrinolytic activity with molecular weight of approximately 35 and $37 \mathrm{kDa}$. Its fibrinolytic activity was completely inhibited by PMSF, but not by EDTA, indicating that the fibrinolytic enzyme in P3 belongs to the serine protease family. Despite the fibrinolytic activity of P3, its protein profile was very week. Hence, it is difficult to identify or characterize its active sources. Obtaining sufficient amounts of $\mathrm{NnV}$ for identification and characterization remains a significant challenge.

Serine proteases in venoms are associated with various biological activities, including hemostatic, cell differentiation, prey digestion as well as affecting the complement system [30]. It mainly disturbs the coagulation cascade through activation or inactivation of platelet aggregation, coagulation, and fibrinolysis [15]. Coagulopathy has not yet been observed in patients stung by jellyfish. Therefore, we speculate the reasons why serine proteases are present in jellyfish venom. Serine proteases can act as spreading factors that may increase their permeability into tissue and promote the spread of venom. They can also form complexes capable of activating the complement cascade through the cleavage of specific components, leading to induction and facilitation of inflammation [34, 35]. Although this study did not investigate the pathological mechanisms of serine proteases, it could explain that inflammatory symptoms provoked by jellyfish envenomation may be partially caused by serine proteases.

\section{Conclusions}

Jellyfish venom research is a very attractive field due to increasing sting accidents and the presence of various bioactive components. Biochemical characterization of toxins can help us understand the pathological symptoms associated with envenomation, so that clinical agents can be developed. Although the present study partially purified a serine protease from $\mathrm{NnV}$, our results could aid the development of clinical management. Furthermore, fibrinolytic properties can be used to treat thrombosis by preventing clot formation [36, 37]. Based on the results of this study, further research can be conducted to isolate serine proteases and investigate the pathological mechanisms involved in inflammatory reactions, in addition to their thrombolytic potential. 


\section{Abbreviations}

NnV: Nemopilema nomurai jellyfish venom; PMSF: Phenylmethanesulfonyl fluoride; SD: Standard deviation; SDS-PAGE: SDS polyacrylamide gel electrophoresis

\section{Acknowledgments}

The authors would like to thank the National Institute of Fisheries Science and the National Research Foundation of Korea for their support.

\section{Funding}

This work was supported by a grant from National Institute of Fisheries Science (R2017046 and15-OE-14) and a National Research Foundation of Korea grant funded by the Korea government (no. NRF-2014R1A2A2A01007245).

\section{Authors' contributions}

EK conceived and designed the study. SKB and HL mainly performed the experiments and wrote the manuscript. SKB and HL contributed equally to this work. MJP, YH and IC analyzed the data. CHH, WDY and CK interpreted and discussed the data. All authors have read and approved the final manuscript.

\section{Ethics approval and consent to participate}

Not applicable.

\section{Consent for publication}

Not applicable.

\section{Competing interests}

The authors declare that they have no competing interests.

\section{Publisher's Note}

Springer Nature remains neutral with regard to jurisdictional claims in published maps and institutional affiliations.

\section{Author details}

${ }^{1}$ College of Veterinary Medicine, Gyeongsang National University, Jinju 660-701, Korea. ${ }^{2}$ Headquarters for Marine Environment, National Fisheries Research \& Development Institute, Shiran-ri, Gijang-eup, Gijang-gun, Busan 619-705, Korea. ${ }^{3}$ Gyeongnam Department of Environment \& Toxicology, Korea Institute of Toxicology, Gyeongnam 52834, Jinju, Korea. Institute of Animal Medicine, Gyeongsang National University, Jinju, 660-701, Korea.

Received: 15 February 2017 Accepted: 3 July 2017

Published online: 19 July 2017

\section{References}

1. Dong Z, Liu D, Keesing JK. Jellyfish blooms in China: dominant species, causes and consequences. Mar Pollut Bull. 2010;60(7):954-63.

2. Fu J, Koo K, Sang AX, Shisler DC. Jellyfish envenomation in an ocean swimmer. Intern Emerg Med. 2014;9(1):103-4.

3. Lynam CP, Gibbons MJ, Axelsen BE, Sparks CA, Coetzee J, Heywood BG, et al. Jellyfish overtake fish in a heavily fished ecosystem. Curr Biol. 2006;16(3): R492-3.

4. Ramasamy S, Isbister GK, Seymour JE, Hodgson WC. The in vivo cardiovascular effects of box jellyfish Chironex fleckeri venom in rats: efficacy of pre-treatment with antivenom, verapamil and magnesium sulphate. Toxicon. 2004;43(6):685-90.

5. Xiao L, He Q, Guo Y, Zhang J, Nie F, Li Y, et al. Cyanea capillata Tentacleonly extract as a potential alternative of nematocyst venom: its cardiovascular toxicity and tolerance to isolation and purification procedures. Toxicon. 2009;53(1):146-52.

6. Kang C, Kim YK, Lee H, Cha M, Sohn ET, Jung ES, et al. Target organ identification of jellyfish envenomation using systemic and integrative analyses in anesthetized dogs. J Pharmacol Toxicol Methods. 2011;64(2):173-9.

7. Bengtson K, Nichols MM, Schnadig V, Ellis MD. Sudden death in a child following jellyfish envenomation by Chiropsalmus quadrumanus. Case report and autopsy findings. JAMA. 1991;266(10):1404-6.

8. Kim DH, Seo JN, Yoon WD, Suh YS. Estimating the economic damage caused by jellyfish to fisheries in Korea. Fish Sci. 2012;78:1147-52.

9. Kawahara M, Uye S, Burnett J, Mianzan H. Stings of edible jellyfish (Rhopilema hispidum, Rhopilema esculentum and Nemopilema nomurai) in Japanese waters. Toxicon. 2006;48(6):713-6.
10. Choudhary I, Lee H, Pyo MJ, Heo Y, Bae SK, Kwon YC, et al. Nemopilema nomurai jellyfish venom treatment leads to alterations in rat cardiomyocytes proteome. Data Brief. 2015;5:884-7.

11. Kang C, Munawir A, Cha M, Sohn ET, Lee H, Kim JS, et al. Cytotoxicity and hemolytic activity of jellyfish Nemopilema nomurai (Scyphozoa: Rhizostomeae) venom. Comp Biochem Physiol C Toxicol Pharmacol. 2009;150(1):85-90.

12. Kang C, Jin YB, Kwak J, Jung H, Yoon WD, Yoon TJ, et al. Protective effect of tetracycline against dermal toxicity induced by jellyfish venom. PLoS One. 2013;8(3):e57658.

13. Lee H, Jung ES, Kang C, Yoon WD, Kim JS, Kim E. Scyphozoan jellyfish venom metalloproteinases and their role in the cytotoxicity. Toxicon. 2011; 58(3):277-84.

14. Swenson S, Markland FS Jr. Snake venom fibrin(ogen)olytic enzymes. Toxicon. 2005;45(8):1021-39.

15. White J. Snake venoms and coagulopathy. Toxicon. 2005;45(8):951-67.

16. Krem MM, Di Cera E. Evolution of enzyme cascades from embryonic development to blood coagulation. Trends Biochem Sci. 2002;27(2):67-74.

17. Li R, Yu H, Xue W, Yue Y, Liu S, Xing R, et al. Jellyfish venomics and venom gland transcriptomics analysis of Stomolophus meleagris to reveal the toxins associated with sting. J Proteome. 2014;106:17-29.

18. Li R, Yu H, Yue Y, Liu S, Xing R, Chen X, et al. Combined proteomics and transcriptomics identifies sting-related toxins of jellyfish Cyanea nozakii. J Proteome. 2016;148:57-64.

19. Weston AJ, Chung R, Dunlap WC, Morandini AC, Marques AC, Moura-daSilva AM, et al. Proteomic characterisation of toxins isolated from nematocysts of the South Atlantic jellyfish Olindias sambaquiensis. Toxicon. 2013;71:11-7.

20. Heo Y, Kwon YC, Bae SK, Hwang D, Yang HR, Choudhary I, et al. Cloning a Chymotrypsin-like 1 (CTRL-1) protease CDNA from the jellyfish Nemopilema nomurai. Toxins (Basel). 2016;8(7):205.

21. Bloom DA, Burnett JW, Alderslade P. Partial purification of box jellyfish (Chironex fleckeri) nematocyst venom isolated at the beachside. Toxicon. 1998;36(8):1075-85.

22. Carrette T, Seymour J. A rapid and repeatable method for venom extraction from cubozoan nematocysts. Toxicon. 2004;44(2):135-9.

23. Bradford MM. A rapid and sensitive method for the quantitation of microgram quantities of protein utilizing the principle of protein-dye binding. Anal Biochem. 1976;72:248-54.

24. Laemmli UK. Cleavage of structural proteins during the assembly of the head of bacteriophage T4. Nature. 1970;227(5259):680-5.

25. Matsubara K, Hori K, Matsuura Y, Miyazawa K. A fibrinolytic enzyme from a marine green alga, Codium latum. Phytochemistry. 1999;52(6):993-9.

26. Heo Y, Kwon YC, Shin K, Yoon WD, Han CH, Yum S, et al. CDNA and gene structures of two phospholipase A2 isoforms, acidic PLA2 PA4 and PLA2 PA3A/ PA3B/PA5, in Nemopilema nomurai jellyfish venom. Toxicon. 2016;122:160-6.

27. Junior VH, Zara F, Marangoni S, Toyama Dde O, de Souza AJ, de Oliveira SC, et al. Identification of two novel cytolysins from the hydrozoan Olindias sambaquiensis (Cnidaria). J Venom Anim Toxins incl Trop Dis. 2014;20(1):10.

28. Lassen S, Wiebring A, Helmholz H, Ruhnau C, Prange A. Isolation of a Nav channel blocking polypeptide from Cyanea capillata Medusae - a neurotoxin contained in fishing tentacle isorhizas. Toxicon. 2012;59(6):610-6.

29. Yanagihara AA, Shohet RV. Cubozoan venom-induced cardiovascular collapse is caused by hyperkalemia and prevented by zinc gluconate in mice. PLoS One. 2012;7(12):e51368.

30. Kini RM. Serine proteases affecting blood coagulation and fibrinolysis from snake venoms. Pathophysiol Haemost Thromb. 2005;34(4-5):200-4.

31. Rodrigues VM, Soares AM, Guerra-Sá R, Rodrigues V, Fontes MR, Giglio JR. Structural and functional characterization of neuwiedase, a nonhemorrhagic fibrin(ogen)olytic metalloprotease from Bothrops neuwiedi snake venom. Arch Biochem Biophys. 2000;381(2):213-24.

32. Terada S, Hori J, Fujimura S, Kimoto E. Purification and amino acid sequence of brevilysin L6, a non-hemorrhagic metalloprotease from Agkistrodon halys Brevicaudus venom. J Biochem. 1999;125(1):64-9.

33. Wang $S, X u X$, Gao S, Zhu S, Rong R, Li B. Purification and partial characterization of a novel fibrinogenase from the venom of Deinagkistrodon acutus: inhibition of platelet aggregation. Protein Expr Purif. 2014;99:99-105.

34. Zychar BC, Dale CS, Demarchi DS, Gonçalves LR. Contribution of metalloproteases, serine proteases and phospholipases A2 to the inflammatory reaction induced by Bothrops jararaca crude venom in mice. Toxicon. 2010;55(2-3):227-34. 
35. Yamamoto C, Tsuru D, Oda-Ueda N, Ohno M, Hattori S, Kim ST. Flavoxobin, a serine protease from Trimeresurus flavoviridis (habu snake) venom, independently cleaves Arg726-Ser727 of human C3 and acts as a novel, heterologous C3 convertase. Immunology. 2002;107(1):111-7.

36. Barros LC, Ferreira RS Jr, Barraviera SR, Stolf HO, Thomazini-Santos IA, Mendes-Giannini MJ, et al. A new fibrin sealant from Crotalus durissus terrificus venom: applications in medicine. J Toxicol Environ Health B Crit Rev. 2009;12(8):553-71.

37. Ferreira RS Jr, de Barros LC, Abbade LPF, Barraviera SRCS, Silvares MRC, de Pontes LG, et al. Heterologous fibrin sealant derived from snake venom: from bench to bedside - an overview. J Venom Anim Toxins incl Trop Dis. 2017;23:21.

Submit your next manuscript to BioMed Central and we will help you at every step:

- We accept pre-submission inquiries

- Our selector tool helps you to find the most relevant journal

- We provide round the clock customer support

- Convenient online submission

- Thorough peer review

- Inclusion in PubMed and all major indexing services

- Maximum visibility for your research

Submit your manuscript at www.biomedcentral.com/submit
Biomed Central 